\title{
Symptomatic Myelopathy Caused by Ossification of the Yellow Ligament
}

\author{
Dong Am Park, Seok Won Kim, Seung Myung Lee, Chong Gue Kim, \\ Suk Jung Jang, Chang II Ju \\ Department of Neurosurgery, College of Medicine, Chosun University, Gwangju, Republic of Korea
}

\begin{abstract}
Objective: This study was performed to describe the clinical presentation, surgical outcome in patients with symptomatic myelopathy caused by ossification of the yellow ligament (OYL).

Methods: The authors reviewed consequent 12 patients in whom posterior decompressive laminectomies were performed for OYL from 1999 to 2005. Diagnostic imagings including simple radiographs, computed tomography and magnetic resonance images were performed in each case. The patients were reviewed to evaluate the clinical presentation, surgical outcome and complications of the operation.

Results: In all patients, OYL was located in the lower thoracic region and all patients presented with numbness on both limbs and pain. Among them, 5 patients presented with gait disturbance due to paraparesis and two patients had sphincter dysfunction. Decompressive laminectomy through a posterior approach using microscope resulted in improvement of symptoms in all patients, but, recovery was incomplete in a half of the patients. The mean postoperative Japanese orthopaedics association (JOA) score was 7.9 when compared with 4.9 in preoperative assessment and the mean recovery rate was $65 \%$. Dural tear was noticed in four patients, so dural repair was performed, but there were no neurological deficits related to neural injury.

Conclusion: OYL is an uncommon cause of myelopathy but it can lead to debilitating thoracic myelopathy. Careful decompressive laminectomy can achieve favorable results.
\end{abstract}

Key Words: Ossification • Yellow ligament $\cdot$ Decompressive laminectomy

\section{INTRODUCTION}

Ossification of the yellow ligament $(\mathrm{OYL})$ resulting in neurologic deficits is a rare disease. Since OYL was first reported by Polgar in 1920 with lateral radiographs ${ }^{9}$, reports have shown that it was relatively common in the Asian population and a large majority of these cases have been reported in Japanese subjects ${ }^{1,6,10}$. Etiology of OYL is still not fully understood, but association of OYL with other hyperostotic conditions has been documented. The authors report twelve patients with symptomatic myelopathy caused by OYL to discuss the epidemiology, clinical presentation, surgical outcome and complications.

\footnotetext{
- Received: October 4, 2012 - Revised: November 12, 2012

- Accepted: December 14, 2012

Corresponding Author: Seok Won Kim, MD, PhD

Department of Neurosurgery, School of Medicine, Chosun University,

588, Seosuk-dong, Dong-gu, Gwangju-city 501-717, Republic of Korea

Tel: +82-62-220-3126, FAX: +82-62-227-4575

E-mail:ns64902@hanmail.net/chosunns@chosun.ac.kr

*This study was supported by chosun university fund in 2012 .
}

\section{MATERIALS AND METHODS}

Posterior decompressive laminectomies for symptomatic myelopathy caused by OYL were conducted at our institute from 1999 to 2005 . The results were analyzed case by case. Patients (four men and eight women) who ranged from 42 to 76 in their age (mean age 60.5) have lesions which were varied from T8-T9 to T12-L1 level. Evaluation was achieved by plain radiographs, computed tomography (CT) scan, and magnetic resonance imaging (MRI) studies. The radiologic work-up provided the characteristics of OYL (i.e., location, number of affected segments, associated spine pathologies), showed possible spinal cord involvement, and accompanying narrowing of the spinal canal. Ten patients had single-level involvement, and the other two patients had double level involvement (Fig. $1 \&$ Fig. 2). Two cases were attributed to trivial traumatic injury. All patients had lower limb pain and numbness and five patients had gait disturbance owing to motor weakness, which involved spasticity or imbalance (posterior cord lesion) in varying degree. Two patients had sphinter dysfun- 

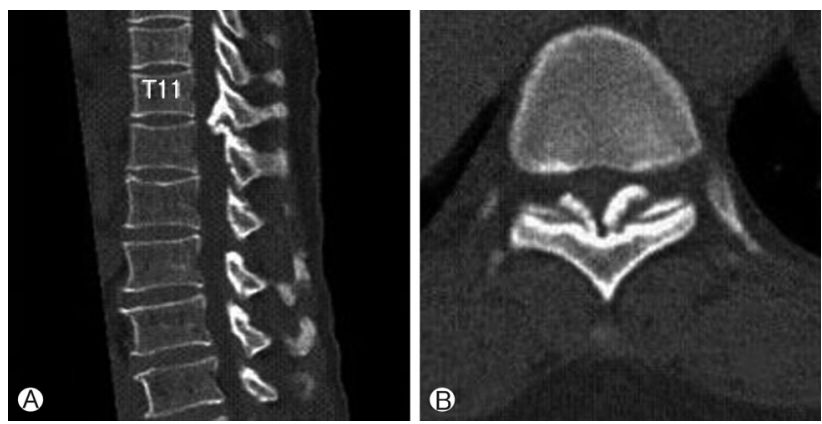

Fig. 1. A 62-year old female patient (case 1). A \& B. Computed tomography scans show bilateral ossification of yellow ligament at T11-12 level.
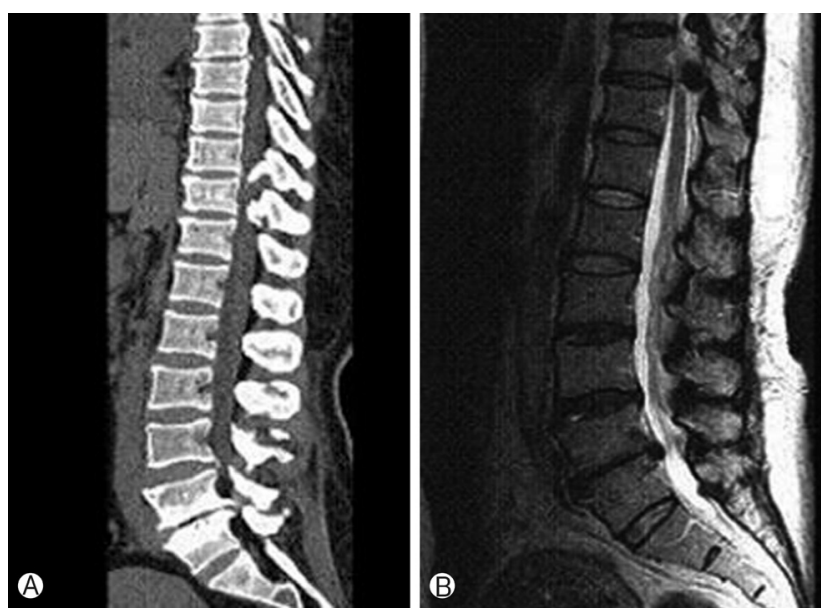

Fig. 2. A 63-year old male patient (case 2). A: Sagittal computed tomography scan shows ossification of yellow ligament at T9T10 and T10-T11 level accompanying lumbar spinal stenosis due to bony spur at L4-L5 level. B: T2-weighted sagittal magnetic resonance image reveals severe cord compression at T9-T10 and T10-T11 level.

ction. Back pain was not a main feature in all patients. The range of dysfunction resulting from myelopathy, as assessed by the Japanese orthopaedics association (JOA) scoring system, was 3-10 with a mean score of 4.9. All patients received posterior decompressive laminectomy including the laminae, ossified yellow ligament, and partial medial facet with the aid of high-speed burr and small-angled kerrison punch. Instrumentation wasn't performed in any patient. Specimens were sent for histologic study.

\section{RESULTS}

All patients improved at the end of the evaluation period, but recovery was incomplete in a half of the patients. Mean follow-up period was $24.2 \pm 12.0$ months. They are all ambula-
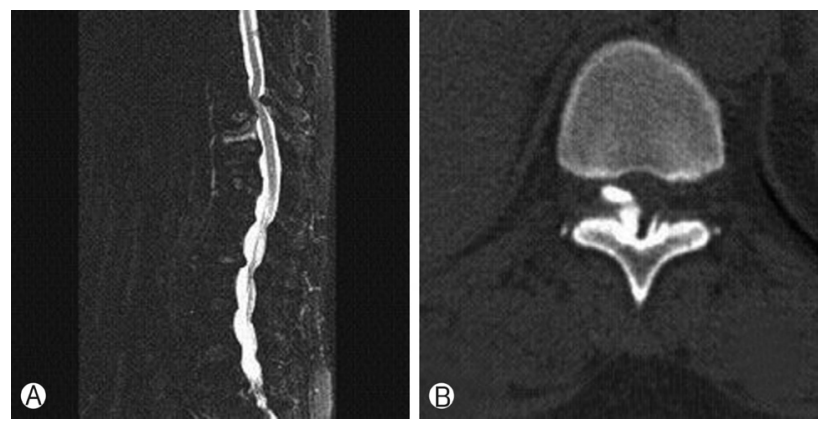

Fig. 3. A 67-year old female patient (case 3). A \& B: Fat suppression magnetic resonance image and computed tomography scan show fresh compression fracture at $\mathrm{T} 11$ level and ossification of yellow ligament at T10-T11 level.

tory with or without assistance, numbness and pain have been improved in all patients, but two of them couldn't regain sphincter control. The mean postoperative JOA score was 7.9 when compared with 4.9 in preoperative assessment. The recovery scale was calculated by the following equation:

$$
\begin{aligned}
& \text { The rate of recovery }(\%)= \\
& \frac{\text { (postoperative score - preoperative score) }}{\text { (total score - preoperative score) }} \times 100
\end{aligned}
$$

The range of recovery rate was from $35 \%$ to $90 \%$ and the mean was $65 \%$. MRI showed the existence of a hyperintense signal in the spinal cord in 2 patients (case $4 \&$ case 9 ) and also showed the association of OYL with narrowing of the lumbar spinal canal in 3 patients (case 2, case $7 \&$ case 10). Two patients (case $3 \&$ case 9), who had been asymptomatic all along became paraparesis after she slipped down. Five patients presented with gait disturbance due to paraparesis and two patients had sphincter dysfunction. MRI scan revealed OYL accompanying osteoporotic compression fracture at T10 level (Fig. 3). Posterior decompressive laminectomies were performed. Dural tear was noticed in four patients as an attempt was made to dissect the adhesion of the dura. Dural repair by artificial dural graft was performed, and fibrin glue was injected. There was no sign of persistent cerebrospinal fluid leakage and meningocele. Moreover, neither postlaminectomy kyphotic deformity nor deep wound infection was identified in the present study. At microscopic evaluation of the operative specimens, there was evidence of a progressive disappearance of the ligament tissue replaced by mature lamellar bone through a process of enchondral ossification.

\section{DISCUSSION}

OYL is an uncommon disease causing compressing or radimyelopathy ${ }^{11)}$. Kudo et al. ${ }^{3)}$ reviewed 1744 lateral chest radio- 
graphs and revealed OYL in $6.2 \%$ of male and $4.8 \%$ of female patients; most of the cases were asymptomatic. Although the average age was older and female was predominant in this study, OYL usually affects men younger than 50 years in most cases. The cause of OYL is still unknown. It is thought that the ossification originates from within the ligamentum itself. Ossified lesions are composed of lamellar bone with developed Haversian canals. Early lesions are composed of an ossifying front with fibrocartilaginous cell proliferation at the margins. Ono et al. ${ }^{7}$ found that fibrocartilaginous cell proliferation and matrix hyperplasia with cartilaginous conversion were observed in every case of OYL. Most of the patients with OYL presented with progressive myelopathy as manifested by pain in lower limb, motor and sensory deficits, gait disturbance, and urinary dysfunction. Interestingly, one patient in this present study, who had been asymptomatic all along became paraparesis and showed accompanying osteoporotic compression fracture after minor slip and fall down injury. Similar to this study, OYL is most commonly observed in the lower thoracic spine between T9 and T12 in approximately $80 \%$ of cases ${ }^{8,13}$. These levels appear to be particularly prone to degenerative processes owing to the high tensile force present in the posterior column. That is to say, the larger range of rotation allows a larger tensile force to be applied to the yellow ligament thus increasing the frequency of OYL. OYL is found at the superior and inferior extremities of 2 adjacent laminae, to which they are joined ${ }^{2,5)}$. They can even close the space between the laminae by uniting the overlying and underlying adjacent laminae, to which they are connected at an obtuse angle. Myelography combined with CT can show spinal cord compression but is, at present, commonly replaced by MRI as the modality of choice for neural elements and the cord. MRI, which was performed for all of our patients, is indispensable for evaluating potential spinal cord involvement ${ }^{12)}$. In the literature, OYL is frequently accompanied by narrowing of the neural canal or as well as by the ossification of other ligaments. We noted this association in 3 of our patients (Table 1). Surgery is the only treatment that can adequately address significant compression of neurologic structures caused by OYL. When ossification causes radicular pain, as a result of a lateral location, unilateral fenestration to resect OYL allows nerve-root decompression. However, in most cases, decompressive laminectomy is the interven-

Table 1. Japanese orthopaedics association score for the assessment of myelopathy

\begin{tabular}{cc}
\hline \hline Score & Neurologic Status \\
\hline Motor dysfunction of lower limbs \\
0 & Unable to walk \\
1 & Able to walk on flat floor with walking aid \\
2 & Able to walk up/downstairs with handrail \\
3 & Lack of stability and smooth reciprocation \\
4 & of gait \\
Sensory deficit in lower limbs \\
0 & Severe sensory loss or pain \\
1 & Mild sensory deficit \\
2 & No dysfunction \\
Sensory deficit in trunk & Severe sensory loss or pain \\
0 & Mild sensory deficit \\
1 & No dysfunction \\
2 & \\
Sphincter dysfunction & Unable to void \\
0 & Marked difficulty in micturition \\
1 & Minor difficulty in micturition \\
2 & No dysfunction \\
3 &
\end{tabular}

Table 2. Patients characteristics

\begin{tabular}{|c|c|c|c|c|c|c|c|c|}
\hline $\begin{array}{l}\text { Patients } \\
\text { No. }\end{array}$ & $\begin{array}{l}\text { Age(ys)/ } \\
\text { Sex }\end{array}$ & $\begin{array}{l}\text { Cousre } \\
\text { Duration }\end{array}$ & Symptoms & Direction & $\begin{array}{l}\text { Ossification } \\
\text { Level }\end{array}$ & $\begin{array}{l}\text { Associated Spine } \\
\text { Pathologies }\end{array}$ & MRI (T2 image) & $\begin{array}{l}\text { Trauma } \\
\text { History }\end{array}$ \\
\hline Case 1 & $62 / F$ & 4 months & Pain (lower limbs) & bilateral & 1 level & - & - & - \\
\hline Case 2 & $63 / \mathrm{M}$ & 3 weeks & Paraparesis & bilateral & 2 level & Lumbar spinal stenosis & - & - \\
\hline Case 3 & $67 / F$ & 5 days & Paraparesis & bilateral & 1 level & Compression fracture & - & 0 \\
\hline Case 4 & $57 / M$ & 2 months & Paresthesia & bilateral & 2 level & - & Hyperintense & \\
\hline Case 5 & $51 / M$ & 1 month & Pain (lower limbs) & bilateral & 2 level & - & - & - \\
\hline Case 6 & $63 / F$ & 3 weeks & Paraparesis & unilateral & 2 level & - & - & - \\
\hline Case 7 & $60 / \mathrm{M}$ & 3 months & Sphincter dysfunction & bilateral & 2 level & Lumbar spinal stenosis & - & - \\
\hline Case 8 & $42 / F$ & 2 months & Paraparesis & bilateral & 2 level & - & - & - \\
\hline Case 9 & $58 / F$ & 5 weeks & Quadriparesis & unilateral & 2 level & - & Hyperintense & 0 \\
\hline Case 10 & $67 / F$ & 5 weeks & Sphincter dysfunction & bilateral & 2 level & Lumbar spinal stenosis & - & - \\
\hline Case 11 & $61 / F$ & 10 days & Pain (lower limb) & unilateral & 1 level & - & - & - \\
\hline Case 12 & $76 / F$ & 3 months & Pain (lower limb) & unilateral & 1 level & - & - & - \\
\hline
\end{tabular}

*OPLL: ossification of posterior longitudinal ligament 
tion of choice because of underlying myelopathy. It should be conducted carefully given that OYL frequently is associated with adherence between the ossification and dura mater ${ }^{14)}$. An air drill may be used to begin decompression by resection of adjacent laminae rostral and caudal to the lesion. In this manner, the area of OYL can be isolated. The OYL is then dissected with caution to separate it from the dura mater. Histopathologic examination of OYL typically finds mature bone. The ligamentum flavum is progressively replaced by lamellar bone through a process of enchondral ossification. This process appears to begin near the facet joint capsule and the ligamentum flavum, where a proliferation of cartilaginous tissue triggers the ossification. More recent studies have shown a high level of plasma fibronectin in patients who had ossification of the posterior longitudinal ligament or the ligamentum flavum ${ }^{4)}$.

\section{CONCLUSION}

OYL is a rare disease that can cause myelopathy mostly at the lower thoracic level. CT established the diagnosis of OYL, while MRI is helpful for showing spinal cord involvement. The treatment of OYL is based on laminectomy with precautionary measures against adhesions to the dura mater.

\section{REFERENCES}

1. Cho YH, Moon SM, Roh SW, Joen SR, Rhim SC: Surgical outcome and prognostic factors of ossified ligamentumflavumof the thoracic spine. J Korean Neurosurg Soc 32:424-430, 2002

2. Kubota T, Kawano H, Yamashima T, Ikeda K, Hayashi M, Yamamoto S: Ultrastructural study of calcification process in the ligamentumflavum of the cervical spine. Spine 12(4):317-323, 1987
3. Kudo S, Ono M, Russell WJ: Ossification of thoracic ligamentaflava. AJR Am J Roentgeno 1141(1):117-121, 1983

4. Miyamoto S, Yonenobu K, Ono K: Elevated plasma fibronectin concentrations in patients with ossification of the posterior longitudinal ligament and ossification of the ligamentumflavum. Spine 18(15):2267-2270, 1993

5. Miyasaka K, Kaneda K, Sato S, Iwasaki Y, Abe S, Takei H, et al: Myelopathy due to ossification or calcification of the ligamentumflavum: radiologic and histologic evaluations. AJNR Am J Neuroradio 14(3):629-632, 1983

6. Okada K, Oka S, Tohge K, Ono K, Yonenobu K, Hosoya T: Thoracic myelopathy caused by ossification of the ligamentumflavum. clinicopathologicstudy and surgical treatment. Spine 16 (3):280-287, 1991

7. Ono k, Yonenobu K, Miyamoto S, Okada K: Pathology of ossification of the posterior longitudinal ligament and ligamentumflavum. Clinorthop Relat Res 359:18-26, 1999

8. Pascal-Mousselard H, Smadja D, Cabre P, Raynaud M, Catonne Y: Ossification of the ligamentaflava with severe myelopathy in a black patient. acase report. Spine 23(14):1607-1608, 1998

9. Polgar F: Uberinter akuellewirbelverkal kung. Fortschr Geb Rongenstr Nuklearmed Erganzungsband 40:292-298, 1920

10. Shiokawa K, Hanakita J, Suwa H, Saiki M, Oda M, KajiwaraM : Clinical analysis and prognostic study of ossified ligamentumflavum of the thoracic spine. J Neurosurg 94(2 Suppl):221-226, 2001

11. Song JY, Park JH, Roh SW: Ossified ligamentumflavum causing cervical myelopathy. Korean J Spine 9(1):24-27, 2012

12. Sugimura H, Kakitsubata Y, Suzuki Y, Kakitsubata S, Tamura S, Uwada O, et al: MRI of ossification of ligamentumflavum. J Comput Assist Tomogr 16(1):73-76, 1992

13. Williams DM, Gabrielsen TO, Latack JT, Martel W, Knake JE: Ossification in the cephalic attachment of the ligamentumflavum. ananatomical and CT study. Radiology 150(2):423-426, 1984

14. Yonenobu K, Ebara S, Fujiwara K, Yamashita K, Ono K, Yamamoto $\mathrm{T}$, et al: Thoracic myelopathy secondary to ossification of the spinal ligament. J Neurosurg 66(4):511-518, 1987 